\title{
Continuing Medical Education
}

\section{Anaesthetic manage- ment of the brain dead for organ donation}

\begin{abstract}
An increasing number of anaesthetists is being called upon 10 manage organ donors during organ retrieval procedures. We briefly describe the technical aspects of the surgical procedure together with a guide to the anaesthetic management. The aims of the latter may be summarized as the "Rule of 100": systolic blood pressure $>100 \mathrm{mmHg}$, urine output $>100 \mathrm{ml} \cdot \mathrm{hr}^{-l}$, $\mathrm{PaO}_{2}>100 \mathrm{mmHg}$, haemoglobin concentration $>100 \mathrm{~g} \cdot \mathrm{L}^{-l}$. Common management problems (hypotension, arrhythmias, diabetes insipidus, oliguria, and coagulopathy) are discussed in detail. The intraoperative management of the brain-dead organ donor provides the anaesthetist with the challenge of a major surgical procedure in a subject with important physiological derangements.
\end{abstract}

Les anesthésistes sont appelés de plus en plus à devoir s'occuper des "donneurs" d'organes durant l'opération de prélèvement. Nous décrivons brièvement la technique chirurgicale et pròposons un plan d'action pour l'anesthésiste. On peut simplifier en lui proposant de s'en tenir à la "règle des 100 ": tension artérielle systolique $>100 \mathrm{mmHg}$, débit urinaire $>100 \mathrm{ml}$. $h^{-l}, \mathrm{PaO}_{2}>100 \mathrm{mmHg}$, hémoglobine $>100 \mathrm{~g} \cdot \mathrm{L}^{-1}$. Nous revoyons aussi le traitement des; problèmes les plus fréquents : hypotension, arythmie, diabète insipide, oligurie et coagulopathie. Le prélèvement d'organe après mort cérébrale pose à l'anesthésiste, le défi d'une intervention chirurgicale majeure chez un sujet à la physiologie altérée.

\section{Key words}

ANAESTHESIA: transplantation;

BRAIN: death.

From the *Department of Anaesthesia, University Hospital, London, Ontario, Canada and †Department of Anesthesia, University of Mississippi Medical Centre, Jackson, Mississippi.

Address correspondence to: Dr. A.W. Gelb, Department of Anacsthesia, University Hospital, 339 Windermere Road, London, Ontario N6A 5A5 Canada.
Adrian W. Gelb mB ChB FRCPC, Kerri M. Robertson MD FRCPC ${ }^{\dagger}$

Over the past two decades, organ transplantation has become popular as a therapeutic modality and, indeed, has become the treatment of choice for selected patients with end-stage cardiac, liver, or kidney failure. With the continued improvement in immunosuppressive techniques, tissue preservation, surgical and intensive care procedures, the number and range of successful organ transplants has increased so that demand now far exceeds the available supply. As fewer than four per cent of all deaths result in a potentially suitable donor and, unfortunately, less than $10-15$ per cent of these suitable donors become actual donors, excellent perioperative care needs to be provided to optimize end-organ function and allow for utilization of this limited resource. ${ }^{1,2}$

A potential donor is any previously healthy individual who has suffered an irreversible catastrophic brain injury of known aetiology. Exclusion criteria have recently been reviewed. ${ }^{3}$ Contraindications to organ donation include old age (greater than 65-70 yr), untreated systemic sepsis, most extracranial malignancies, and the presence of transmissible diseases not amenable to antibiotic therapy (e.g. , hepatitis, cytomegalovirus virus, HIV). The rigidity to which absolute or relative exclusion criteria are adhered varies from centre to centre and may be influenced by the urgency of the need. Therefore, the suitability of any potential organ donor should be discussed with the regional transplant centre.

\section{Declaration of brain death}

Once a potential organ donor has been identified, the first step in management is the declaration of brain death by physicians not directly participating in the procurement procedures. In brain death, the irreversible cessation of brain function is the primary event as defined by coma, unresponsiveness to stimuli, and the absence of brain stem function. ${ }^{4}$ There are no universally accepted guidelines for the declaration of brain death. All, however, require a clinical declaration which may need to be supplemented by other confirmatory tests. The anaesthe- 
tist participating in the donor operation should verify that the medical and legal documentation of family consent for organ donation and certification of death conform to local and hospital requirements.

\section{The donor operation}

Donor organs may be divided into perfusible organs (kidneys, liver, heart, lung(s), pancreas, and bowel) and nonperfusable organs and tissues (eyes, skin, bone, heart valves, and dura). It is the primary responsibility of the anaesthetist to provide vigilant care of the heart beating multiorgan donor in an effort to maintain the function of perfusible organs until the moment of removal. Anaesthetists have no direct role in the removal of nonperfusible tissues.

Retrieval of the organs may be performed by surgeons from one's own hospital or by an itinerant retrieval team consisting of one or more surgical groups and transplant coordinators who work in concert with the donor institution operating room team of surgeons, nurses and anaesthetists. In the latter situation, the timing of the procedure may be dictated by flight schedules and weather conditions rather than the convenience of the operating room schedule.

There has been a gradual evolution of surgical techniques from the meticulous and time consuming in vivo dissection and removal of warm organs to a technique of en block procurement and in situ core cooling of organs. ${ }^{5.6}$ The latter approach reduces the extent of ischaemic injury from surgically induced arterial spasm producing uneven cooling of the donor organ.

Multiple organ retrieval is a sterile procedure which takes approximately three to four hours. The donor is placed supine on the operating table, usually with the arms tucked in at the sides as this facilitates easy access to both the thorax and the abdomen. A midline incision from the suprasternal notch to the pubis is made and the sternum is split. The supporting ligaments of the liver are divided. An incision is made in the crux of the diaphragm and the supraceliac aorta is encircled with an umbilical tape. The inferior mesenteric vein is then cannulated to allow flushing of the liver through the portal system (Figure). A ligature is also placed around the aorta at the level of the inferior mesenteric artery to allow for cannulation and aortic perfusion. The liver and kidneys are usually examined for any gross abnormalities which would preclude transplantation.

For donor heart excision, the pericardium is opened and the heart examined for any abnormalities including dyskinetic segments. The aorta and superior vena cava are freed from the right pulmonary artery and the azygous vein is ligated and divided. After the anaesthetist has administered intravenous heparin, a cardioplegia catheter

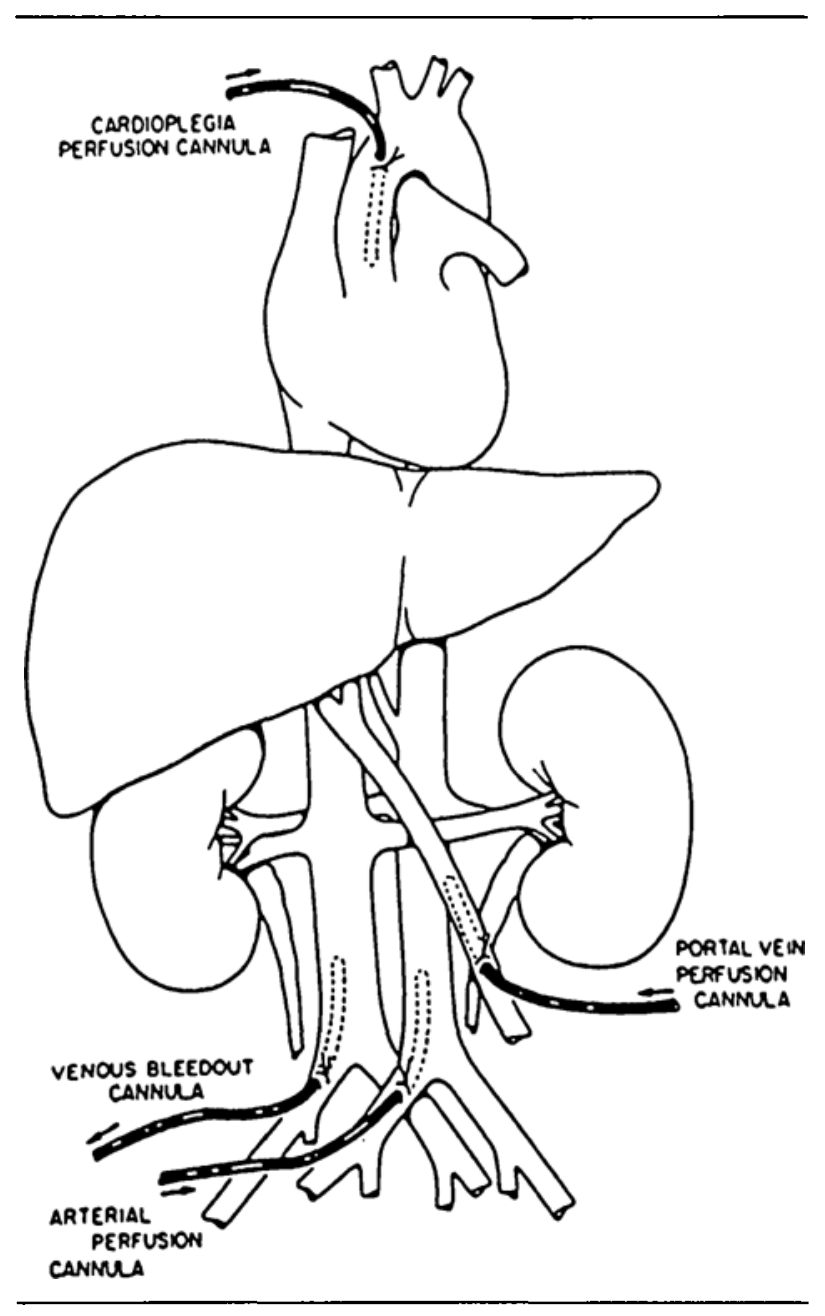

FIGURE Sites of cannulas for in situ perfusion during multi-organ procurement. (Reproduced with permission from Experience of a Canadian multi-organ transplant service, Canadian Medical Association Journal 1986; 135: 197-203.)

is inserted into the ascending aorta, the distal aorta is ligated and an aortic perfusion cannula is inserted. With inflow occlusion of the superior vena cava (with withdrawal of the CVP catheter as necessary) and crossclamping of the aorta proximal to the innominate artery and at the diaphragm, preservation solutions for cardiac, lung, kidney, and gastrointestinal organs are infused simultaneously. Outflow for the perfusate is obtained by dividing the inferior vena cava or cannulating it near its abdominal bifurcation to prevent venous hypertension with congestion of the liver and kidneys. The spleen and omental lymph nodes are removed for tissue typing.

For heart-lung(s) procurement, the above technique is slightly modified. The mediastinal pleura and the trachea are dissected from their attachments. This may result in significant mechanical hypotension and difficulties with ventilation and oxygenation. After insertion of the car- 
TABLE I Preoperative check list

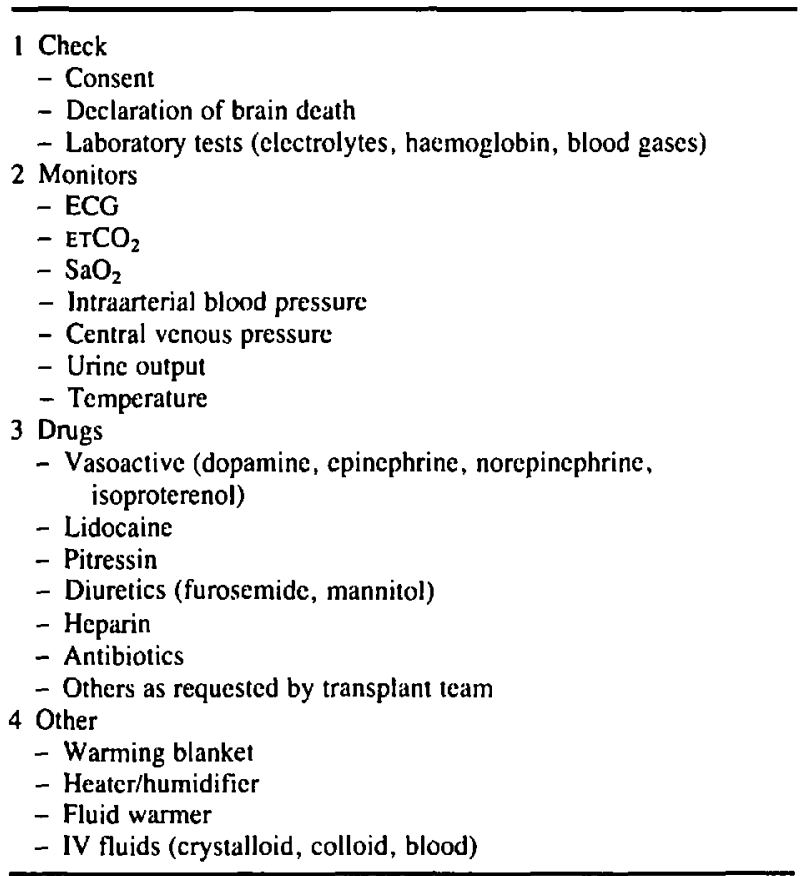

dioplegia catheter into the root of the aorta, a double cannula is inserted into the main pulmonary artery for flushing the pulmonary arteries. Following cardioplegia to the heart, the pulmonary arteries are flushed and the lungs manually ventilated slowly with four breaths $\cdot \min ^{-1}$. The pulmonary perfusate may contain prostaglandin $E_{1}$ which could result in profound hypotension. Ventilatory support is then discontinued, the airways suctioned and the endotracheal tube removed. With division of the superior vena cava and trachea, the heart and lungs are removed from the chest.

\section{Anaesthetic requirements}

The aims of anaesthetic management are to maintain optimal organ perfusion and cellular oxygenation together with fluid, electrolyte and acid-base balance. This will help reduce early postoperative dysfunction from ischaemic injury. Obviously, providing analgesia and unconsciousness are unnecessary. The goals of perioperative management can be summarized as the "rule of 100s":

$\begin{array}{ll}\text { Systolic blood pressure } & >100 \mathrm{mmHg} \\ \text { Urine output } & >100 \mathrm{ml} \cdot \mathrm{hr}^{-1} \\ \mathrm{PaO}_{2} & >100 \mathrm{mmHg} \\ \text { Haemoglobin } & >100 \mathrm{~g} \cdot \mathrm{L}^{-1}\end{array}$

As the organ donor operation is a major surgical procedure which can be associated with substantial blood loss and physiological derangements, the operating room should be prepared accordingly (Table I). Required monitoring includes an electrocardiogram, central venous pressure, arterial blood pressure, urine volume, core temperature, end tidal $\mathrm{CO}_{2}$ and capillary oxygen saturation. If the donor has a pulmonary artery catheter in place, this should be used but routine insertion for intraoperative use is not required. Arterial blood gas analysis, haemoglobin concentration, serum electrolytes and glucose should be measured hourly.

The operating room, in addition to being stocked with drugs used routinely for anaesthesia, should be adequately equipped with a supply of inotropic agents including dopamine, epinephrine, and norepinephrine. Each one of these latter drugs should be appropriately diluted and available for administration by means of a calibrated infusion system. As ventricular arrythmias and bradycardia are frequent, lidocaine and isoproterenol should be immediately available. Bradycardia in the brain dead is resistant to atropine. ${ }^{7}$ A prudent measure is to have the cardiac resuscitation cart in the operating room. Other drugs that should be available include pitressin or arginine vasopressin (DDAVP) for the treatment of diabetes insipidus, furosemide, mannitol, and heparin (300 $\mu$. $\mathrm{kg}^{-1}$ ). In an attempt to improve donor organ function, additional therapy may be required according to the transplant team's request or current fashion, e.g., alphablockers, steroids, triiodothyronine.

Brain death results in a loss of temperature regulation, leaving the organ donor poikilothermic. In an attempt to maintain a core temperature above $34^{\circ} \mathrm{C}$, the operating room should be warmed, a heating blanket placed on the operating table, and fluid warmers used for all intravenous infusions. ${ }^{8}$ An efficient gas heater/humidifier may also help slow the often inexorable decrease in body temperature. $^{9}$

The donor operation requires exposure of the abdominal and thoracic cavities which may result in massive fluid shifts and blood loss. Generally, a donor from whom the heart, liver, and kidneys are being removed will require the infusion of two units of packed red cells to maintain adequate oxygen delivery. Routinely, the donor should be cross-matched for four units of packed red blood cells. Pressure infuser bags suitable for use with both blood products and crystalloid should be available in the operating room.

Once the operating room is appropriately equipped, as described above, the organ donor may be brought to the operating suite. The location and adequacy of intravenous access, use of vasoactive and other drugs, and the latest laboratory results should all be noted.

The donor's lungs should be ventilated with the same $\mathrm{FIO}_{2}$ and positive end-expiratory pressure (PEEP) as was used in the intensive care unit although it would be prudent to increase the $\mathrm{FIO}_{2}$ to 1.0 until the first $\mathrm{PaO}_{2}$ has 
been obtained. If the lungs are to be transplanted, an $\mathrm{FIO}_{2}$ of less than 0.4 and a PEEP of less than $7.5 \mathrm{cmH}_{2} \mathrm{O}$ is preferred. In all circumstances, the aim is to keep the $\mathrm{PaO}_{2}$ in the range of $75-150 \mathrm{mmHg}$. Brain death with resultant hypothermia causes a reduction in metabolic rate and thereby $\mathrm{CO}_{2}$ production so that the usual ventilatory settings and gas flow rates would result in hypocapnia. This could cause an impairment in tissue oxygenation and perfusion and uneven distribution of the organ preservation solution. The $\mathrm{PaCO}_{2}$ should, therefore, be kept near or slightly above the normal range.

The declaration of brain death requires the loss of cerebral and brain stem reflexes, leaving responses of spinal origin intact. ${ }^{10,11}$ Reflex neuromuscular activity should be expected and may range from muscle twitching to complex movements of the limbs and trunk. For the unsuspecting in the operating room, this can be most disconcerting and staff may require frequent reassurance that the donor is indeed brain dead. As the surgical procedure necessitates extensive retraction and in order to avoid reflex muscle movements, a neuromuscular blocking drug such as pancuronium should be given at the beginning of the procedure.

Reflex haemodynamic responses to nociceptive stimulation also occur frequently. ${ }^{12}$ This, too, may create the impression that the donor is not brain dead. Current definitions of brain death require the absence of medullary respiratory reflexes but not those of cardiovascular reflex control. ${ }^{4}$ The response may be due to reflexes involving the brain stem vasomotor areas which may still be intact, spinal reflexes, or adrenal medullary stimulation by a reflex arc. Therapy includes weaning from vasopressors and on occasion the use of a vasodilator such as nitroprusside or nitroglycerin. Insoflurane may be the most convenient.

Anaesthetic care should continue until surgical occlusion of the proximal aorta and the start of in situ flushing of the organs. Thereafter, all monitoring and supportive measures should be discontinued. A note should be made of the time of aortic cross-clamping as this represents the start time of cold ischaemia for the transplantable organs.

\section{Common management problems}

Brain death results in derangement of normal homeostatic mechanisms. This ultimately (hours to days) leads to irreversible cardiac arrest. ${ }^{13.14}$ After the declaration of brain death, management which begins in the intensive care unit and continues throughout the donor operation, consists of intervening in the natural course of the events leading to somatic death. We describe here some of the more common problems pertinent to the care of the organ donor in the operating room (Table II). A more extensive review with management algorithms is available. ${ }^{3}$

\section{Hypotension}

Hypotension should be anticipated in all organ donors. Contributing factors include hypovolaemia, derangements of vasomotor control mechanisms, hypothermia, endocrine abnormalities, and left ventricular dysfunction. ${ }^{15}$ Hypovolaemia may be the result of therapeutic dehydration in an effort to decrease cerebral oedema, inadequate resuscitation after haemorrhage, diabetes insipidus, or osmotic diuresis due to hyperglycaemia.

The possibility that endocrine dysfunction may contribute to the haemodynamic deterioration of the donor has been a topic of recent interest. In brain-dead animal models, a progressive reduction in circulating cortisol, insulin and free triiodothyronine $\left(T_{3}\right)$ has been found. ${ }^{16}$ These investigators have recommended that organ donors be treated with an endocrine "cocktail" in order to avoid haemodynamic deterioration and to improve the ultimate function of the transplanted organs. ${ }^{16.17}$ While we and others have substantiated the reduction in free $T_{3}$, the acute changes seen in the thyroid profile are more consistent with the "sick euthyroid syndrome" than true hypothyroidism. No correlation between these endocrine changes and haemodynamic stability of the donor was found ${ }^{18,19}$ Evidence supporting $T_{3}$ therapy in donors includes a postulated relationship between (1) the lack of myocardial intracellular thyroid hormone and myocardial cell degeneration, and (2) clinically significant improvement, both haemodynamic and metabolic, in graft function with treatment. These beneficial effects may represent a pharmacological effect independent of the physiological status of the donor, and requires further evaluation. Therefore, at present, such therapy is not recommended.

Initial management should be comprised of aggressive restitution of the intravascular volume. One should aim to keep the CVP in the 10-12 $\mathrm{mmHg}$ range and the systolic blood pressure greater than $100 \mathrm{mmHg}$. It is, however, important to avoid overhydration which may precipitate cardiac overdistension, pulmonary oedema, and liver congestion with cellular injury during cold storage. The ideal choice of fluid is still a matter of dispute but crystalloid may be used initially and then, if necessary, a combination of crystalloid and colloid. The use of large volumes of dextrose-containing solutions may compound preexisting hyperglycaemia with its attendant risks of osmotic diuresis and electrolyte abnormalities and should, therefore, be used with caution. Blood should be

TABLE II Common problems in organ donors

\begin{tabular}{ll}
\hline Hypotension & Arrychmias \\
Diabetes insipidus & Oliguria \\
Anaemia/coagulopathy & Hypothermia \\
Electrolyte imbalance & Hyperglycaemia \\
Acid-base abnormalities &
\end{tabular}


transfused to keep the haematocrit at approximately 30 per cent.

The use of inotropes may be needed to maintain an adequate blood pressure on a temporary basis during fluid resuscitation or for persistent hypotension despite an adequate central venous pressure (CVP $12 \mathrm{mmHg}$ ). Dopamine is usually regarded as the initial vasopressor of choice because at low infusion rates $\left(<5 \mu \mathrm{g} \cdot \mathrm{kg}^{-1}\right.$. $\left.\mathrm{min}^{-1}\right)$ it causes vasodilatation of the renal, mesenteric, and coronary arterial vascular beds and thus should minimize end-organ ischaemic damage compared with other sympathomimetic agents. ${ }^{20}$ At higher infusion rates, these vasodilatory effects are lost and end-organ ischaemia may occur. As one of dopamine's actions involves presynaptic modulation of norepinephrine release, prolonged dopamine infusion may cause depletion of norepinephrine stores in the heart which could result in myocardial dysfunction after transplantation. ${ }^{21.22}$ Also, there is concern that dopamine may augment the structural damage which may result from sympathetic outpouring during the process of brain death. For these reasons, some transplant teams prefer not to use dopamine. Our practice is to use up to $10 \mu \mathrm{g} \cdot \mathrm{kg}^{-1} \cdot \mathrm{min}^{-1}$ dopamine and thereafter to add norepinephrine while titrating the dopamine back to $3 \mu \mathrm{g} \cdot \mathrm{kg}^{-1} \cdot \mathrm{min}^{-1}$ for renal protection. ${ }^{23}$ If increasing doses of norepinephrine are required, then we switch to epinephrine. As there is a shortage of good data from organ donors on which to base the choice of inotropes, there are widely divergent opinions on what represents optimal therapy. It is, therefore, prudent to discuss the inotropic management with the transplant team.

Dobutamine is a potent inotrope with no direct effects on renal, splanchnic, or liver blood flows although the increase in cardiac output may result in an increase in organ blood flow. ${ }^{24}$ Although it is an effective alternative to dopamine in some patients, we have been disappointed by the large number of patients who do not tolerate dobutamine's beta receptor stimulating effects which cause peripheral vasodilatation. The combined use of arginine vasopressin (DDAVP) with low-dose epinephrine has been reported to produce prolonged haemodynamic stability in brain-dead patients without causing worsening of liver of renal functions. ${ }^{25}$ At present, such an approach is regarded as experimental.

\footnotetext{
Arrhythmias

Atrial and ventricular arrhythmias as well as conduction defects occur frequently in organ donors. ${ }^{14}$ Contributing factors include electrolyte and arterial blood gas disorders, hypotension with myocardial ischaemia, hypothermia, inotropic infusions, myocardial contusions, and increased intracranial pressure. Therapy should follow the usual guidelines except for bradycardia which is resistant to
}

atropine in the brain dead. ${ }^{7}$ Ultimately all brain-dead individuals undergo terminal arrhythmias which are resistant to therapy. ${ }^{14}$ Cardiopulmonary resuscitation should be performed, at least for a limited period of time and especially if the donor is already in the operating room. Although this may preclude use of the heart for transplantation, the other organs may still be utilizable.

\section{Diabetes insipidus}

Diabetes insipidus is a common complication of brain death and results from the complete or partial loss of the production and release of antidiuretic hormone from the posterior pituitary. ${ }^{26}$ It presents as a massive hypotonic diuresis that bears no relationship to the intravascular fluid volume. If left untreated, it will result in hypovolaemia, hyperosmolality, hypernatraemia, hypermagnasaemia, hypokalaemia, hypophosphataemia and hypocalcaemia. The urinary losses should be replaced on a volume for volume basis with the composition of crystalloid solution dictated by frequent serum electrolyte and osmolality measurements. If urine output consistently exceeds $300-500 \mathrm{ml} \cdot \mathrm{hr}^{-1}$, pitressin should be started. ${ }^{27}$ The subcutaneous or intramuscular routes should not be used as absorption is unreliable in hypovolaemic and hypothermic individuals. For intraoperative use, a titratable continuous infusion of aqueous pitressin (start at 0.1 units $\cdot \mathrm{min}^{-1}$ ) offers the greatest flexibility, although some patients may come to the operating room having already received a dose of the longer acting arginine vasopressin (DDAVP). Some transplant teams, however, are concerned that the coronary and renal vasoconstriction produced by vasopressin may result in organ ischaemia or uneven distribution of the preservation solutions during flushing. We believe that the benefits of a pitressin infusion (minimised electrolyte abnormalities, fluid shifts, and the volume of cold solutions required for infusion) outweighs the potential concern about organ ischaemia. A compromise solution would be to discontinue the pitressin infusion about an hour before the planned infusion of preservation solutions.

\section{Oliguria}

Oliguria usually reflects the effects of hypovolaemia and hypotension and will respond to management of these problems. The aim should be to achieve a urine output in excess of $1 \mathrm{ml} \cdot \mathrm{kg}^{-1} \cdot \mathrm{hr}^{-1}$. However, on occasion it may reflect renal dysfunction resulting from earlier episodes of renal ischaemia which may have been compounded by the use of nephrotoxic drugs. If restoration of circulating blood volume and blood pressure are not effective, then small doses of furosemide $(20-40 \mathrm{mg})$ or low-dose dopamine $\left(3 \mu \mathrm{g} \cdot \mathrm{kg}^{-1} \cdot \mathrm{min}^{-1}\right)$ may be used. The choice should be discussed with the transplant team. 


\section{Coagulopathy}

This is an uncommon but exceedingly difficult problem to manage intraoperatively. It may be caused by the release of fibrinolytic substances or plasminogen activators from the ischaemic brain or by other processes set in motion by the initial injury. ${ }^{28}$ The onset of a severe coagulopathy may necessitate the rapid transfer of the donor from the intensive care unit to the operating room for organ retrieval. Management includes the administration of red blood cells, clotting factors, and platelets. Epsilon amino caproic acid (EACA) is not recommended as it may cause microvascular thrombosis in the donor organs.

\section{Conclusion}

The intraoperative management of the brain-dead organ donor provides the anaesthetist with the challenge of a major surgical procedure in a subject with significant physiological derangements. An understanding of the surgical procedure and the pathophysiology of the changes that occur with brain death will enhance one's ability to manage successfully the multiorgan donor and ultimately prevent early graft dysfunction in the recipient.

\section{References}

1 Gilmore A. Procuring donor organs: firm but friendly encouragement required. Can Med Assoc J 1986; 134 : 932-7.

2 Kolata $G$. Organ shortage clouds new tranplant era: organs are used from only one in ten potential donors; some say legislation is needed to make more organs available. Science 1983; 221: 32-3.

3 Soifer $B E$, Gelb $A W$. The multiple organ donor: identification and management. Ann Int Med 1989; 110: 814-23.

4 Nelson $R F$. Determination of brain death. Can J Neurol Sci 1986; 13: 355-8.

5 Starzl TE, Miller C, Broznick B, Makowka L. An improved technique for multiple organ harvesting. Surg Gynccol Obstet 1987; 165: 343-8.

6 Rolles $K$, Jamieson $N V$. Donor operation and preservation of the liver. Calne $R$ (Ed.). Liver transplantation: the Cambridge King's College hospital experience, 2nd ed., Orlando: Grune \& Stratton, 1987; 141-56.

7 Vaghadia H. Atropine resistance in brain-dead organ donors. Anesthesiology 1986; 65: 711-2.

8 Zell SC, Kurtz KJ. Severe exposure hypothcrmia: a resuscitation protocol. Ann Emerg Med 1985; 14: 339-45.

9 Stone DR, Downs JB, Paul WL, Perkins HM. Adult body temperature and heated humidification of anesthetic gases during general anesthesia. Anesth Analg 1981; 60: 736-41.

10 Jorgenson EO. Spinal man after brain death. The unilateral extension-pronation reflex of the upper limb as an indication of brain death. Acta Neurochirurgica 1973; 28 : 259-73.

11 Ropper $A H$. Unusual spontancous movements in braindead patients. Neurology 1984; 34: 1089-92.

12 Wetzel RC, Setzer N, Stiff JL, Rogers MC. Hemodynamic responses in brain dead organ donor patients. Anesth Analg 1985; 64: 125-8.

13 Black PM. Brain death. N Engl J Med. 1978; 299: 33844, 393-401.

14 Logigian EL, Popper AH. Terminal electrocardiographic changes in brain-dead patients. Neurology 1985; 35 : 915-8.

15 Nishimura $N$, Miyata $Y$. Cardiovascular changes in the terminal stage of discasc. Resuscitation 1984; 12: 175 80.

16 Novizzky D, Wicomb $W N$, Cooper $D K C$, Rose AG, Fraser $R C$, Barnard $C N$. Electrocardiographic, hemodynamic, and endocrine changes during experimental brain death in the Chacma baboon. J Heart Transplant 1984; 4: 63-9.

17 Novitzky D, Cooper DK, Reichart B. Hemodynamic and metabolic responses to hormonal therapy in brain-dead potential organ donors. Transplantation 1987; 43: 852-4.

18 Robertson KM, Hramiak IM, Gelb AW. Endocrine changes and haemodynamic stability after brain death. Transplant Proc 1988; 21: 1197-8.

19 Howlett TA, Keogh AM, Perry Les, Touzel R, Rees $L H$. Anterior and posterior pituitary function in brainstem-dead donors. Transplantation 1989; 47: 828-34.

20 Goldberg $L I$. Cardiovascular and renal actions of dopamine: potential clinical applications. Pharmacol Rev 1972; 24: 1-29.

21 Weiner $N$. Norepinephrinc, epinephrine, and the sympathomimetic amines. In: Gilman AC, Goodman LS, Rall TW, Murad F (Eds.). Goodman and Gilman's Pharmcological Basis of Therapeutics. 6th ed., New York: MacMillan 1985; 145-80.

22 Novitzky D, Cooper DKC, Wicomb WM, Reichart B. Hemodynamic changes, myocardial injury, and pulmonary edema induced by sympathetic activity during the development of brain death in the baboon. Transplant Proc 1986; 13: 609-12.

23 Hilberman $M$, Maseda J, Stinson EB et al. The diuretic properties of dopamine in patients after open-heart operation. Anesthesiology 1984; 61: 489-94.

24 Robie NW, Goldberg LI. Comparative systemic and regional hemodynamic effects of dopamine and dobutamine. Am Heart J 1975; 90: 340-5.

25 Yoshioka T, Sugimoto H, Uenishi M et al. Prolonged hemodynamic maintenance by the combined administration of vasopressin and epinephrine in brain death: a clinical study. Neurosurgery 1986; 18: 565-7. 
26 Outwater KM, Rockoff MA. Diabetes insipidus accompanying brain death in children. Neurology 1984; 34:

1243-6.

27 Hays RM. Agents affecting the renal conservation of water. In: Gilman AC, Goodman LS, Rall TW, Murad F

(Eds.). Goodman and Gilman's Pharmacological Basis of Therapeutics. 6th ed., New York: MacMillan, 1985;

908-19.

28 Miner ME, Kaufman HH, Graham SH et al. Disseminated intravascular coagulation fibrinolytic syndrome following head injury in children: frequency and prognostic implications. J Pediatr 1982; 100: 687-91.

\section{Multiple choice questions}

1 The best management of hypotension is:
A An endocrine "cocktail" $\left(\mathrm{T}_{3}\right)$
B Atropine
C Inotropes
D Restitution of IV volume
E Correct hypothermia

2 Diabetes insipidus:

A Is an infrequent occurrence in brain-dead patients

B May result in hypovolaemia, hypematraemia and hypokalaemia

C Is best treated with IM pitressin

D Causes a massive hypertonic diuresis

E Should be treated with fluid restriction

3 Organ preservation depends primarily on:
A Steroids
B Core cooling
C $\mathrm{T}_{3}$
D Surgical technique
E Alpha blockers

4 Bradycardia responds to:
A Isoproterenol
B Correction of hyperthermia
C Cardioversion
D Atropine

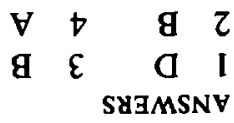

